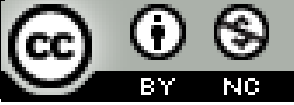

\title{
A SUPREMACIA DA RAZÃO TECNOCIENTÍFICA E A "INUTILIDADE" COMO CONDIÇÃO PARA O FILOSOFAR
}

\author{
The supremacy of the techno-scientific reason and the "inutility" as a condition \\ to philosophize
}

\author{
João Cardoso de Castro \\ UFRJ \\ Murilo Cardoso de Castro \\ UERJ
}

\begin{abstract}
Resumo: Nosso trabalho aborda um pensamento não raro, especialmente entre aqueles mais engajados na "vida ativa", seja nos laboratórios da academia ou nos quefazeres mundanos, a "inutilidade da abordagem filosófica", onde se considera imperativo e imediato "fazer" ou "agir". Por se tratar o tema proposto filosoficamente, corre-se o risco de "inutilidade" de nossa abordagem do próprio tema. Todavia, diante do progresso irrefreável da técnica, e sua dominaç̃̃o por sobre todas as expressões da vida humana, aí incluída a própria filosofia, entendemos - com Martin Heidegger - que é precisamente nesta condição que a filosofia encontra o seu "fim", não no sentido de um esgotamento de suas possibilidades, mas como "lugar", "finalidade", "abertura" para a busca-de-si. Para levar a cabo esta empreitada, discutimos uma interpretação muito própria da abordagem filosófica e sua qualificação tendo como contraponto o pensar científico. Na parte final, refletimos sobre os conceitos de inutilidade e circularidade enquanto condição para a abertura do pensar filosófico e, por conseguinte, para uma retomada autêntica da busca-de-si.
\end{abstract}

Palavras-chave: Inútil, Filosofia, Ciência, Técnica

\begin{abstract}
Our work deals with a not infrequent thought, especially among those who are more engaged in the "active life", whether in the laboratories of the academy or in worldly affairs, the "uselessness of the philosophical approach", where it is considered imperative and immediate "to do" or "to act". By addressing the topic proposed philosophically, there is a risk of "uselessness" of our approach to the subject itself. However, in the face of the unstoppable progress of technique and its domination over all expressions of human life, including philosophy itself, we understand - with Martin Heidegger - that it is precisely in this condition that philosophy finds its "end", not in sense of a depletion of its possibilities, but as "place," "purpose," "openness" to self-seeking. In order to carry out this work, we have discussed a very specific interpretation of the philosophical approach and its qualification, addressing the scientific thinking as counterpoint. In the final part, we reflect on the concepts of uselessness and circularity as a condition for the opening of philosophical thinking and, consequently, for an authentic resumption of self-seeking.
\end{abstract}

Keywords: Useless, Philosophy, Science, Technique

\section{Introdução}

Este ensaio se depara de imediato com um paradoxo: a possível "inutilidade" de sua pretensa abordagem filosófica no trato do tema que o título propõe. Ao mesmo tempo, oferece em sua pretensão a oportunidade de exercitar uma questão filosófica fundamental: "o que é?", redirigida agora, à própria abordagem filosófica ora em exercício. Uma reflexão desta natureza tem por objetivo repensar a filosofia como extrema possibilidade, conforme nos precavê Martin Heidegger, alertando ao mesmo 
tempo para o risco de engodo nesta possibilidade ${ }^{1}$ Neste sentido, é necessário fazer ressoar uma vez mais seu aspecto originário, para além da instrumentalização da razão tão em voga nos dias de hoje. Expressões como "caixa-de-ferramenta" ou "instrumento de análise", corriqueiramente utilizadas nas áreas onde a Filosofia se encontra absorvida, dão o tom técnico que pretendemos denunciar e opor neste ensaio.

Entendemos que, assim como todos os campos de investigação, também a Filosofia foi impregnada pelo domínio planetário da técnica, expressão consagrada por Heidegger para se referir à maneira como a técnica se espraia por todas as dimensões da experiência humana ${ }^{2}$. Não se trata "apenas" de uma explosão quantitativa do aparato tecnológico que nos cerca no dia-a-dia. Também nosso pensar foi abduzido pela técnica e, por este motivo, a era da técnica é, para Heidegger, aquela onde nos colocamos em fuga do "verdadeiro" pensamento. A predominância do pensar calculador caracteriza "a crescente ausência de pensamentos [...] num processo que corrói o âmago mais profundo do homem moderno", diz Heidegger (2001, p. 11). Na esteira da constatação heideggeriana, Carneiro Leão é ainda mais contundente quando qualifica nosso tempo como "tão decadente que grande é o risco de perdermos até as condições de ídentificar a decadência e apreciá-la como decadência".

Embora pareça prevalecer um "colorido" apocalíptico nessas considerações, há também, no seio dessa mesma época, uma possibilidade autêntica. Isto é, parafraseando o poeta Hölderlin, "onde mora o perigo é lá que também cresce o que salva" (apud. HEIDEGGER, 2002b, p. 31). A era da técnica é também a de uma experiência privilegiada da angústia. A noção de angústia (em alemão, Angst), em Heidegger, tem uma conotação diferente, em profundidade, daquela que vige nos dias de hoje ${ }^{3}$. Nela e por ela, somos confrontados com aquele espaço familiar, onde estamos imersos no senso-comum (das Man), na existência ingênua e tranquilizadora das relações técnicas, das significações já constituídas, enfim, do ser-no-mundo, para o lugar da brusca revelação da condição original do homem: a de saber que nada sabe

Assim, a era do domínio planetário da técnica indica que a Filosofia chega ao seu fim, embora esse "fim" não deva ser compreendido no sentido de um "término", mas de finalidade, sentido, lugar. Segundo Heidegger: "que dizemos nós quando falamos do fim da Filosofia? Temos a tendência de compreender o fim de algo em sentido negativo como a pura cessação, como a cessação de um processo, quando não como ruína e impotência" (HEIDEGGER, 1999, p. 96). E complementa: "o antigo significado de nossa palavra "fim" (Ende) é o mesmo que o da palavra "lugar' (Ore) [...] O fim da Filosofia é o lugar, é aquilo em que se reúne o todo de sua história, em sua extrema possibilidade" (ibid.).

\footnotetext{
1 “[...] o perigo mais monstruoso em filosofia consiste em ludibriar, porque todos os esforços não têm o caráter massivo de um experimento científico natural ou aquele de uma fonte histórica. Mas onde o perigo máximo de ludibriar está, há também a possibilidade extrema [höchste Möglichkeit] para a genuinidade do pensar e do questionar. O sentido de fazer filosofia consiste em despertar a necessidade por esta genuinidade e em mantêla desperta." (HEIDEGGER, 1997, p. 293)

2 "No imperialismo planetário do homem organizado tecnicamente, o subjectivismo do homem atinge o seu mais elevado cume, a partir do qual ele se estabelecerá na planície da homogeneidade organizada, e aí se instalará. Esta homogeneidade torna-se o mais seguro instrumento do domínio completo, isto é, do domínio técnico sobre a Terra." (HEIDEGGER, 2002a, p. 113-114)

3 "O porquê de a angústia se angustiar é o ser-no-mundo ele mesmo. [...] A angústia retira, assim, do Dasein a possibilidade de, no decair, entender-se a partir do "mundo" e do público ser-do-interpretado. Ela projeta o Dasein de volta naquilo por que ele se angustia, seu próprio poder-ser-no-mundo. A angústia isola o Dasein em seu ser-no-mundo mais-próprio que, como entendedor, se projeta essencialmente em possibilidades. Com o porquê do se angustiar, a angústia abre, portanto, o Dasein como ser possível, ou melhor, como aquele que unicamente a partir de si mesmo pode ser como isolado no isolamento." (HEIDEGGER, 2012a, p. 525)

4 "O nada se revela na angústia - mas não enquanto ente. Tampouco nos é dado como objeto. A angústia não é uma apreensão do nada. Entretanto, o nada se toma manifesto por ela e nela, ainda que não da maneira como se o nada se mostrasse separado, "ao lado" do ente, em sua totalidade, o qual caiu na estranheza. Muito antes, e isto já o dissemos: na angústia deparamos com o nada juntamente com o ente em sua totalidade." (HEIDEGGER, 1999, p. 57)
} 


\section{A "abordagem filosófica"}

Convém agora deixarmos claro o que entendemos por "abordagem filosófica". Para tal, é indispensável esclarecer inicialmente três pontos fundamentais: "abordagem", "filosófica" e a questão "o que é?", ou, em nosso caso, "o que é o sendo que é?", ou seja: o que é o sendo (abordlagem filosófica) que é (abordagem filosófica)?; o paradoxo de um ensaio que investiga a abordagem filosófica através de uma abordagem filosófica, e ainda mais guarda a pretensão de responder quanto a sua "inutilidade".

Conforme já explicitamos, a importância do que aqui se trata é imensa, levando em conta as inúmeras vezes em que se menciona, via oral ou textual, esta expressão "abordagem filosófica", como algo perfeitamente claro e entendido por todos. Entendimento este que pressupõe ainda outro: o tema que está se tratando, ou vai se tratar, segundo "uma abordagem filosófica", tem mais profundidade ou mais densidade ou ainda, mais teor reflexivo, do que aquilo que é falado ordinariamente sobre o mesmo tema.

Fato é que a "abordagem filosófica" se destaca das demais abordagens possíveis de um tema qualquer. Ao se destacar, para muitos, ela soa como uma abstração, um isolamento do tema, de fatores comuns de seu contexto ordinário. Ou seja, estima-se, em geral, que a "abordagem filosófica" seja uma espécie de distanciamento de situações concretas. Estima-se que este distanciamento, que permite uma melhor visão da questão e de seu contexto, faz com que os sentidos utilitário e prático desta abordagem venham a se tornar questionáveis, e até, muitas vezes, que se afirme um desvio em elucubrações onde esses sentidos sejam totalmente abandonados. Supõe-se, em geral, que o tratamento filosófico de qualquer tema seja mais um "jogo de palavras", uma quimera que carece de praticidade, e até mesmo de qualquer utilidade ${ }^{5}$.

Prosseguindo em nossa investigação, nos voltamos à filosofia, que qualifica esta abordagem como pertencente a seu quadro. Agora nossa indagação é sobre sua natureza, sobre "o que é a filosofia?" . A expectativa neste trajeto é sermos conduzidos à exploração da abertura evocada pela questão "o que é?" (consagrada no grego antigo como ti estĩ). Enquanto questão primal, desde a filosofia antiga, passando por seu questionamento à própria filosofia, esperamos não apenas iluminar a questão e o questionado, alcançando alguma clareza sobre a filosofia em si mesma.

Saber os [discursos ou situações] interrogar, com efeito, significa saber os interpretar, saber sob que ângulo de ataque os tomar, por qual bordo. A filosofia aqui não supõe conhecimentos prévios: é um gesto ou um olhar a apreender. Frequentemente discursos e textos, mas também gestos e mesmo objetos só são incompreensíveis porque não sabemos à qual questão respondem, e que não nos pomos nem mesmo a questão. Saber interrogar, é buscar perceber o invisível, as questões às quais os fatos, as palavras e os comportamentos respondem; e é compreender que estas questões não são forçosamente as nossas, que não compreendemos tudo. É também compreender que estas respostas podem abrir novas questões, às quais elas não respondem, e às quais nem sonhamos. Há, portanto, algo como um aprendizado da interrogação, é ao mesmo tempo uma formação da inteligência e uima abertura propriamente ética: a integração progressiva das questões de outro e dos outros pontos de vista a nossa percepção e a nossa concepção do mundo. (ABEL, 2000 p.25)

\footnotetext{
${ }^{5}$ Nosso propósito fica ainda mais claro ao parafrasear o que Heidegger diz sobre a questão "o que é a filosofia?", substituindo "filosofia" por "abordagem filosófica" nesta citação (1999, p. 27): "Que é isto - a filosofia?, falamos sobre a filosofia. Perguntando desta maneira, permanecemos, num ponto acima da filosofia e isto quer dizer fora dela. Porém, a meta de nossa questăo é penetrar na filosofia, demorarmo-nos nela, submeter nosso comportamento às suas leis, quer dizer, "fillosofar". O caminho de nossa discussão deve ter por isso não apenas uma direção bem clara, mas esta direção deve, ao mesmo tempo, oferecer-nos também a garantia de que nos movemos no âmbito da filosofia, e não fora e em torno dela."
} 
Saber o melhor "bordo de ataque" de um discurso evoca a palavra "abordagem", que é originária da marinharia, do verbo "abordlar" significando "acostar (uma embarcação) junto a (um porto, uma costa, ou uma outra embarcação)". Temos, em nosso caso, uma figura de retórica, quando chamamos uma "abordagem" de "filosófica". Ou seja, no sentido figurado estaríamos a "acostar nosso barco de pensamentos a um tema", porém utilizando "amarras" filosóficas para sustentar este acostamento.

Seguindo a metáfora da abordagem, o que de fato se passa é que, a exemplo do abordar da marinharia, temos que nos pôr na mesma direção de um tema qualquer, segundo um dispôr filosófico. Temos que, em continuidade, alcançar e acompanhar a dinâmica de pensamento exigida pelo tema, para então, alinhados lado a lado, na mesma direção e convívio, realizarmos então a "abordagem" com as devidas e necessárias "amarras filosóficas". Para esta abordagem, todo o sentido é, portanto, decorrente da filosofia, que deve nos guiar em toda abordagem: no seguir a direção, alcançar, acompanhar, alinhar e, enfim, realizar.

Antes, porém de examinar a filosofia que deve servir de guia, vamos tentar ver o mais claro possível o que nos cabe diretamente nesta empreitada filosófica e que foi resumido no verbo abordar. Trata-se de uma ação? Certamente, no sentido marinheiro do verbo. Mas no sentido figurado, que estudamos, trata-se mais e melhor de uma "atulação". E a diferença significativa, está em que não se age, não se faz, não se produz. Atua-se, no sentido de estar no exercício de um ato de ser, em nosso caso, filosófico. $\mathrm{Na}$ atuação se é, na ação se faz.

No "atuação" (praxis) filosófica, figurada pelo "abordar", se requer discernimento (phronesis), um passo aquém da sabedoria (sophia), já uma demonstração de apreço (philia) por esta, ou seja, philo-sophia. Na ação produtora (poiesis) de fatos, no "abordar" marinheiro, se requer a arte (techne) da marinharia, para se alcançar o resultado, o fato da abordagem. Resumindo, na praxis se exige uma atuação regida pela phronesis, na poiesis é necessária a regência da techne. Aqui cabe refletir sobre a primeira.

Examinemos agora a ordem de sub-atos consecutivos, mas simultâneos, que elencamos no "abordar filosófico": direcionar, alcançar, acompanhar, alinhar e realizar, no sentido de "tornar real", a abordagem. Ao tomar a direção filosófica, abandonamos toda e qualquer agenda prévia, todo e qualquer propósito pessoal, toda e qualquer meta a ser alcançada. Assim como uma embarcação que deseja abordar outra, deve abandonar sua direção anterior para navegar na direção daquela que pretende abordar, da mesma maneira, este deve ser o primeiro ato de uma abordagem filosófica.

Quando Husserl convoca em sua fenomenologia o "retorno às coisas mesmas", ele adota um tom possível da abordagem filosófica. Em seu caso, sua proposta é de retorno desde as coisas empíricas, à constituição das coisas enquanto coisas. Direcionarse segundo uma investigação do "coisar", que ponlha entre parênteses tudo que se tem por aceito segundo a "atitude natural" face às coisas. Este direcionar-se ao tema, guiado pela fenomenologia, acata tão somente o fenômeno, o aparecer da coisa, o coisar, e não o que quer que se tenha de social, histórico, cultural ou científico sobre a coisa.

Tomada a direção do tema, sob a guia da fenomenologia, por exemplo, é preciso alcançá-lo para poder abordá-lo. Quando dizemos alcançar enfatizamos um esforço de pensar que se concentre única e exclusivamente sobre o tema a ser abordado. É preciso, na abordagem fenomenológica, o exercício da epoche: purgar o tema de qualquer agenda prévia ou preconceitos. Qualquer cogitação que ornamente o tema, que o enfeite de considerações de toda natureza, que aplique "colorações" diversas ao que aparece como tal, só serve para dificultar ainda mais o alcance à questão "o que é?"

Alcançado o tema é possível acompanhá-lo, ou seja, fazer companhia ao mesmo. Quando falamos de fazer companhia, lembramos que "companheiro" quer dizer "comer do mesmo pão". O tema alcançado serve agora de alimento para o pensar, tornando-se digno de pensar. Este é um passo indispensável e uma condição necessária para sua abordagem final: seu conhecimento (de co-gnoscere = saber com), e por esta intelecção (noesis) alcançar a "gnose", deixar brillhar o noûs. Porém, antes é preciso o alinhamento filosófico com o tema. 
Acompanhando o tema, trabalha-se sobre o alinhamento com o mesmo. Desde Platão é proposto um método de alinhamento com um tema filosófico: a dialética (de dialegesthai $=$ conversar). A dialética é a tecedura que se tece pela intelecção do tema. Esta tecedura, como em qualquer tecido, percorre os eixos verticais e horizontais da urdidura, que guiam a trama do tema, determinando a amarração necessária para sua abordagem. Estes eixos poderíamos assemelhar às verticais do ser cruzando as horizontais do estar.

Afinal chegamos a culminação da abordagem, realizando-a, ou seja, tornando-a real. O ato de ser filosófico que tornamos transparente em seus sub-atos consecutivos, mas simultâneos, evidencia-se com a atuação desimpedida do noûs, enquanto último nível de desvelamento (aletheuein), dentre os cinco identificados por Aristóteles na Ética a Nicômaco (VI, 3), que veremos mais adiante. Neste sentido, poderia se pensar que o que foi dito sobre "abordagem" vale não somente para a "filosófica", mas igualmente para qualquer outra. Por exemplo, na comparação entre a "abordagem filosófica" e a "abordagem científica", um olhar superficial sobre os sulb-atos enumerados os encontrará igualmente consecutivos e simultâneos em ambas abordagens. Qual seria então a diferença entre estas abordagens? Certamente a qualificação. Por conta desta, é necessário examinar cada sub-ato na realização de uma e outra abordagem, antes mesmo de entrarmos no estudo da qualificação de "filosófica".

Começando pela "direção", temos na abordagem filosófica uma abertura para acolher a direção que o tema nos convida a tomar. É necessário adotar a direção do tema ele mesmo, sem agenda, como dissemos. É necessário pôr entre parênteses todos os préconceitos que possamos ter sobre o tema, para poder segui-lo enquanto tal. $\mathrm{Na}$ abordagem científica, ao contrário, a direção do tema é imposta pelo projeto de pesquisa científica, que funciona como uma rede de conceitos que captura o tema, determinando a direção a ser tomada em sua pesquisa. Kant (2001, p. 18) já denunciava esta natureza perigosa do pensar científico:

Quando Galileu fez rolar no plano inclinado as esferas, com uma aceleração que ele próprio escolhera, quando Torricelli fez suportar pelo ar um peso, que antecipadamente sabia idêntico ao peso conhecido de uma coluna de água, ou quando, mais recentemente, Stahl transformou metais em cal e esta, por sua vez, em metal, tirando-lhes e restituiindo-lhes algo, foi uima iluminação para todos os físicos. Compreenderam que a razão só entende aquilo que produz segundo os seus próprios planos; que ela tem que tomar a dianteira com princípios, que determinam os seus juízos segundo leis constantes e deve forçar a natureza a responder às suas interrogaçōes em vez de se deixar guiar por esta; de outro modlo, as observações feitas ao acaso, realizadas sem plano prévio, não se ordenam segundo a lei necessária, que a razão procuira e de que necessita. A razão, tendo por um lado os seus princípios, únicos a poderem dar aos fenômenos concordantes a autoridade de leis e, por outro, a experimentação, que imaginou segundo esses princípios, deve ir ao encontro da natureza, para ser por esta ensinada, é certo, mas não na qualidade de aluno que aceita tudo o que o mestre afirma, antes na de juiz investido nas suas funçōes, que obriga as testemunhas a responder aos quesitos que lhes apresenta. Assim, a própria física tem de agradecer a revolução, tão proveitosa, do seu modo de pensar, unicamente à ideia de procurar na natureza (e não imaginar), de acordo com o que a razão nela pôs, o que nela deverá aprender e que por si só não alcançaria saber; só assim a física enveredou pelo trilho certo da ciência, após tantos séculos em que foi apenas simples tateio.

Esta diferença fundamental já suficiente para determinar os caminhos totalmente diversos das abordagens e a consecução dos demais sub-atos: na filosófica, uma abertura ao ou um pôr-se à escuta do tema; na científica, um fechamento e uma exploração do tema segundo uma matriz de pensamento em uma determinada região do 
fenômeno $0^{6}$. Por conseguinte, "alcançar" o tema na abordagem científica não representa um desafio em si, pois o projeto de pesquisa já o definiu de antemão, ou seja, não se busca mais o tema enquanto tal, mas o tema enquanto pré-definido pelo projeto de pesquisa, ou seja, o modelo do tema. Da mesma maneira, "acompanhar" o tema é seguir este modelo doravante de modo disciplinado, metodológico. Neste sentido "alinhar" com o tema é, de fato, apenas calibrar o modelo para que seja mais controlável a abordagem. Esta abordagem, qualificada de científica, enquanto realização final do projeto de pesquisa, geralmente se dá de modo consequente, reunindo e analisando os "dados" coletados segundo o modelo do tema determinado pelo projeto de pesquisa.

As diferenças apontadas a cadla sub-ato de uma abordagem, caso esta se dê em modo filosófico ou científico, são apenas ressonâncias de um imenso abismo entre estes qualificadores que desde o nascimento da ciência e da técnica modernas ganhou grandes proporções. Para uma aproximação deste abismo entre filosofia e ciência seria preciso muito mais argumentação do que é possível em um ensaio, mas vamos tentar ser concisos, porém sem deixar de nos ater à essência do abismo.

\section{A qualificação de "filosófica"}

Se nos fosse solicitado dizer em poucas palavras o que é este abismo entre a abordagem filosófica e a abordagem científica, diríamos: o abandono da questão originária "o que é?", ao qual se aliou um pré-conceito: aquele de o que é o ser humano. A indagação primal da filosofia foi registrada em sula certidão de nascimento na Grécia antiga sob a forma da questão do ser, formulada principalmente como "o que é?". Esta questão foi abandonada e seu questionar ainda o é, reiteradamente, pela aceitação de pré-definições sobre o que quer que seja, especialmente na abordagem científica. Dentre estas pré-definições, a mais grave e de maior repercussão, talvez explicando tudo mais, é o pré-conceito de uma resposta já dada, compartilhada e consagrada, à questão "o que é ser humano?".

Este pré-conceito vicia, desvirtua ou adultera, as conclusões do exame ou investigação sobre um tema, especialmente segundo a abordagem científica. Sem a permanente abertura à questão "o que é?" e em especial "o que é ser humano?" temos o risco de uma possível fraude do que quer que se possa afirmar sobre um tema de estudo. Não estamos dizendo que estas questões devem estar respondidas explicitamente no exame do tema, mas certamente o estão implicitamente na abordagem, constatações e conclusões.

Assim, poderia se contestar que essa questão - "o que é?" - é justamente aquela que mantém o fogo aceso da ciência e da técnica modernas. É exatamente o que pretendemos examinar, como o fizemos em relação às abordagens filosófica e científica. A questão "o que é?" tem toda aparência de uma questão fundamental que justamente a ciência tenta responder. Entretanto, há muitos aspectos a examinar sobre esta questão do ponto de vista filosófico ou científico. Mas há ainda algo de mais relevante: a ciência aplica esta questão "o que é?" segundo um recursivo e insistente pré-conceito de "o que é ser humano". Ou seja, em seu projeto de pesquisa em que investiga o que é algo, qualquer que seja, não admite questionar também, concomitantemente, "o que é ser humano?". Este ser humano que ali aborda algo, cujo único sentido legítimo é dado justamente por este ser humano, é pré-determinado e assim não questionado. Nietzsche e Foucault souberam como poucos equacionar a genealogia deste abismo entre abordagens filosófica e científica com a expressão contundente: "a morte do homem"?

\footnotetext{
${ }^{6}$ Para Heidegger (2002b, p. 50): "A teoria assegura para si uma região do real, como domínio de seus objetos. O caráter regional da objetidade aparece na antecipação das possibilidades de pesquisa. Todo novo fenômeno numa área da ciência será processado até enquadrar-se no domínio decisivo dos objetos da respectiva teoria". 7 “Talvez se devesse ver o primeiro esforço desse desenraizamento da Antropologia ao qual, sem dúvida, está votado o pensamento contemporâneo, na experiência de Nietzsche: através de uma crítica fillológica, através de uma certa forma de biologismo, Nietzsche reencontrou o ponto onde o homem e Deus pertencem um ao outro,
} 
A questão fundamental "o que é?" é formulada pela ciência a partir de um modelo, uma representação, construída segundo uma matriz teórica, a partir da qual as hipipóteses também surgem como questões a serem respondidas. A questão assim formulada e as hipóteses levantadas formam uma pesquisa científica com direção, alcance, alinhamento e abordagem previamente definidos. Neste sentido, arriscamos afirmar que a questão "o que é?", conforme pré-disposta pela ciência, não é uma "questão digna de ser pensada", usando esta expressão contundente de Heidegger. Sua resposta e de suas hipóteses são imanentes à representação do que se investiga, ou seja, à matriz teórica e seu modelo da coisa interpelada.

Na abordagem filosófica, se tomada em seu sentido originário, para além de sua desfiguração "moderna", temos um arranjo innteiramente diferente. A crítica de Carneiro Leão (2010, p. 110) é certeira em sua reflexão sobre os nossos tempos:

Para nós, fillhos do petróleo e da técnica, tardos em pensar, se tornou ainda mais difícil este mistério da iden tidade numa época de poluição e consumo. $\mathbb{E}$ por quê?? - Porque temos os ouvidos tão poluídos de ciência e filosofila, temos os olhos tão consumidos pelas utiliidades que já não podemos ver o mistério da pobreza nem ouvir a voz do sillêncio no alarido do desenvolvimento. Desconhecemos o paradox̃o da revolução do pensamento. Já quase não temos sensibilidade para as vibraçōes de nosso destino. $\overline{\mathrm{E}}$ isso, não tanto porque, absorvidos pelas solicitações do consumo, quase não pensamos, mas sobretudo porque, quando pensamos, quase inevitavelmente o fazemos nos moldes da fillosofia e da ciência.

A questão originária "o que é?" fundamentou o pensamento desde os présocráticos. Estes a formularam face à physis, enquanto o que brota de si mesmo, o aparecer da aparência, dando respostas até hoje enigmáticas, como o apeiron (o indefinido, o ilimitado) de Anaximandro, o pyr (o fogo) e o logos de Heráclito, a mesmidade do ser (einai) e do pensar (noein) de Parmênides, entre outras respostas.

Perguntámos: que é isto? Em grego isto é: tí estin. A questão relativa ao que algo seja permanece, todavia, multívoca. Podemos perguintar, por perguntar, poir exemplo: que é aquilo lá longe? Obtemos então a resposta: uma árvore. A resposta consiste em darmos o nome a ưma coisa que não conhecemos exatamente.

Podemos, entretanto, questionar mais: que é aquilo que designamos "árvore"? Com a questão agora posta avançamos para a proximidade do tí estin grego. É aquela forma de questionar desenvolvida por Sócrates, Platăo e Aristóteles. Estes perguntam, por exemplo: Que é isto - o belo? Que é isto - o conhecimento? Que é isto - a natureza? Que é isto - o movimento?

Agora, porém, devemos prestar atenção para o fato de que nas questões acima não se procura apenas uma delimitação mais exata do que é natureza, movimento, beleza; mas é preciso cuidar para que ao mesmo tempo se dê uma explicação sobre o que signiffica o "que", em que sentido se deve compreender o tí. Aquilo que o "que" significa se designa o quid est, to quid. a quidditas, a quididade. Entretanto, a quidditas se determina diversamente nas diversas épocas da filosofia. Assim, por exemplo, a filosofia de Platão é uma interpretação característica daquillo que quer dizer o tr. Ele significa precisamente a ideia. $O$ fato de nós, quando perguntamos pelo tú, pelo quỉd, nos referimos à "ideia" não é

onde a morte do segundo é sinônimo do desaparecimento do primeiro, e onde a promessa do super-homem significa, primeiramente e antes de tudo, a iminência da morte do homem." (FOUCAULT, 1981, p. 472-473)

8 "Desde o início do pensamento ocidental, o ser dos entes se desdobrou, como a única coisa digna de ser pensada. Se pensarmos pelo destino histórico do Ocidente esta constataçăo historiográfica, veremos, então, em que se planta o início do pensamento ocidental: no fato de, na época dos gregos, o ser dos entes ter-se tornado a coisa digna de ser pensada, esse fato é o início do Ocidente, é a fonte escondida de seu destino. Se este início não preservasse o vigor desta vigência, isto é, o recolhimento do que ainda vigora, o ser dos entes não dominaria nossa época, a partir da essência da técnica moderna. Hoje em dia, esta essência maneja todo o globo e, fixa ao ser tal, como o Ocidente o experimenta e representa na forma que a metafísica e a ciência europeia dăo à verdade." (HEIDEGGER, 2002a, p. 201) 
absolutamente evidente. Aristóteles dá uma outra explicação do tí que Platão. Outra ainda dá Kant e também Hegel explica o tí de modo diferente. (HEIDEGGER, 1999, p. 29)

Em todos, no entanto, a questão coadjuvante "o que é ser humano?" está implícita nas diferentes respostas que deixam entrever a capacidade de desvelamento (aletheuein) deste ser humano, onde "o ser que está em jogo no ser deste ente, é sempre meu" (HEIDEGGER, 2006, p. 86).

Em Platão, afirmando o ser humano como a alma e não o corpo', a questão "o que é?", na trilha do "conhece-te a ti mesmo", converteu-se, no questionamento de si mesmo, na pergunta "o que é?" cada um dos modos de excelência (arete) nas diferentes situações humanas (praxis). A cosmologia só interessava ser elaborada enquanto resposta a "o que é ser humano?" e seu contexto, dando sentido às demais questões sobre a alma e suas virtudes, ou seja, a essência do ser humano ${ }^{10}$.

Em Aristóteles, a cosmologia e, em especial a física - agora já no sentido da manifestação do kosmos - assumem a questão "o que é?" no modo onto-teo-lógico, ou seja, como um discurso do ser (ontologia) e do ser supremo (teologia) ${ }^{11}$. Aristóteles discorre também sobre a ordem (kosmos) que se manifesta no contexto da alma, mas também do corpo. Dão-se os primeiros passos para uma episteme que vai vir a ser scientia no Medievo e vai culminar na ciência, na Modernidade (DE CASTRO, 2016). A questão "o que é?" abandona as premissas que a formularam desde os pré-socráticos, de uma physis, para passar a uma natura, de uma ousia para uma essentia, de um kosmos para um mundus, de uma alma-corpo para uma mente-corpo. A redução de o que é se impõe na própria redução de o que é o ser humano, agora uma mente dentro de um corpo em um universo infinito (DE CASTRO, 2017).

A questão originária "o que é?", na antiguidade, seria provocada por aquele "espanto" (thaumazein) que Aristóteles identificou como fonte primal da filosofia, enquanto apreço (philia) à sabedoria (sophia). Em Platão e Aristóteles, e seus principais comentadores, a percepção enquanto ordenamento das sensações, segundo os sentidos da audição, da visão, do tato, da gustação e do olfato, possibilita ao logos (razão) reunir estas impressões. A partir daí seria possível afigurar o que é, com a indispensável ajuda da imaginação e da memória. Esta afiguração se dá sempre em conformidade com as ideias na inteligência, noûs, morada da parte superior da alma, que também é uma ideia (idea). É somente aí então que a questão "o que é?" tem seu verdadeiro eco. O corpo, em tudo isto, é apenas uma "sonda orgânica", um aparato sensório necessário à alma, nas condições de vida na Terra; uma espécie de "robô-sonda" neste mundo físico. É, neste sentido, que Platão alerta que o corpo pode ser uma prisão (sema), caso a alma se submeta exclusivamente a este agregado de percepções e sensações.

A ciência e a técnica modernas respondem à questão "o que é?" reunindo as impressões provenientes das percepções e sensações do corpo, segundo e em

\footnotetext{
9 "No ser humano, todas as coisas dependem da alma." (Mênon, 88e; BRISSON, 2011, p. 1076)

10 "A ideia de que para conhecer a si mesmo se deve conhecer o universo maior do qual se faz parte remonta ao menos até os pré-socráticos; e a afimmação de Heráclito de que "todas as leis humanas são alimentadas por uma Lei única divina" é bem conhecida. A relaçào entre lei (nomos) e natureza (physis) constituiu realmente uma questão calorosamente debatida na época do movimento sofista, e os diálogos de Platão contêm inestimáveis respostas a esse debate principalmente pela tentativa de substituir o que se tomara a seus olhos um divórcio largamente injustificado entre essas duas noções. No que se refere a isso, pode ser dito que sua cosmologia é o melhor exemplo de uma tentativa para harmonizá-las, ao nos mostrar como a normatividade tem que ser fundada nas obras da natureza." (CARONE, 2008, p. 15-16)

11 "Aristóteles designa a ciência que ele caracteriza por contemplar o ente enquanto ente como Filosofia Primeira.

Mas esta considera não apenas o ente na sua entidade, mas igualmente o ente que corresponde puramente à entidade, o ente supremo. Este ente, tó $\Theta \varepsilon$ ťov, o divino, é também chamado, numa peculiar duplicidade, "o ser". A Fillosofia Primeira é, enquanto ontologia, simultaneamente a teologia do deveras ente. De modo mais preciso, deveria ser chamada de Teiologia [Theiologie], A ciência do ente enquanto tal é em si onto-teológica." (HEIDEGGER, 2002, p. 225)
} 
conformidade com o logos científico, regido por uma matriz teórica e seu modelo matemático de representação da realidade. A imaginação científica e a memória de conceitos da matriz teórica não permitem afigurar o que é, mas sim impor uma configuração representativa que doravante vai se constituir como fantasma de o que é, um pseudo o que é. Qualquer participação da inteligência está obliterada pela racionalidade científica ${ }^{12}$, sua matriz teórica e seu modelo de representação da realidade. O que leva Heidegger a afirmar, a contragosto da maioria dos pesquisadores e cientistas, que "a ciência não pensa" (1992, p. 26). Poderíamos ainda agregar, no entanto, que aí justamente está o valor da ciência, sua utilidade e ainda mais: a segurança de seu modus operandi.

Em plena atividade na investigação de o que é segundo percepções e sensações do corpo, sob o domínio da racionalidade científica, a ciência e a técnica modemas têm franquia absoluta para atender às demandas de sua própria representação do corpo. A partir deste modelo ideal do corpo, ciência e técnica modernas fazem progredir indefinidamente o "meio" deste mesmo corpo, tão bem qualificado pelo geógrafo Milton Santos (1996, p. 144), de "meio técnico-científico-informacional". Um exemplo instigante é o desenvolvimento das chamadas biotecnologias dentro da biomedicina, oferecendo todo tipo de intervenções, acréscimos por prótese e modificações genéticas ao corpo humano, para que este venha a atender o que quer que se afirme como mais útil, mais funcional e melhor à vida corporal humana.

Deste modo, a "utilidade" da investigação de o que é só faz sentido dentro desta perspectiva imposta pela ciência e a técnica modernas, ou seja, no dizer de Heidegger, dentro desta metafísica que caracteriza os Tempos Modernos: "a metafísica da representação" (2002a, p. 114). Somente do ponto de vista do corpo e de seu meio é possível se falar de utilidade, de funcionalidade, de capacidade, de competência, enfim, de valor. Estas propriedades não fazem nenhum sentido do ponto de vista filosófico ${ }^{13}$. Na perspectiva do pensamento originário grego, não há nenhuma consideração de utiliidade da questão "o que é?" e muito menos do "que é o ser humano?". Qualquer valor, por conseguinte qualquer ganho, que possa ser atribuído à investigação destas questões dentro da "abordagem filosófica" antiga, é eventual, secundário e derivado, ocasionalmente na administração da vida pessoal, do lar e da cidade. Não obrigatória e exclusivamente em melhorias que cercam o corpo nestas diferentes circunstâncias, mas como uma possibilidade de excelência ou virtude (arete) nestas situações humanas (praxis).

\section{A filosofia é uma inutilidade ${ }^{14}$}

Uma anedota sobre Sócrates pode ajudar a entender este título, ao mesmo tempo que nos introduz a esta última e terceira parte de nosso ensaio. Heidegger (2001, p. 51) relata e comenta esta anedota, provavelmente extraída do Górgias e de algum escrito de Xenofonte:

Umm sofista muito viajado pergunta a Sócrates: "Você continua aí dizendo sempre a mesma coisa? Você torna as coisas fáceis para você". Sócrates responde: "Não, vocês sofistas é que facilitam, porque vocês sempre falam as coisas mais novas e

\footnotetext{
12 Examinando a leitura de Platão feita pelos neoplatônicos, Sorabji $(2005$, p. 13) aponta o lugar desta racionalidade: "O característico eu raciocinativo está abaixo do intelecto da alma, que é um eu superior; há muitos níveis de eu; o intelecto humano é por sua vez derivado da hipóstase divina do Intelecto; o Uno é ainda além do Intelecto".

${ }_{13}^{13}$ “A ciência” não tem a menor ideia de que a sua reivindicação prática imediata não exclui apenas a meditação filosófica, de que nesse instante da extrema relevância prática da ciência irrompe muito antes a mais elevada necessidade de meditação sobre o que nunca pode ser avaliado segundo a utilidade e a eficácia imediata." (HEIDEGGER, 2007, p. 280)

14 "O ato filosófico deixa muito atrás de si a "utilidade", como a procuram no mundo do trabalho. Caracteriza-se por uma 'inutilidade' que não pode abandonar sob pena de não ser mais filosofia." (LUIJPEN, 1973, p. 27)
} 
supernovas e sempre outra coisa. Mas o difícil é dizer a mesma coisa e o mais difícil ainda: dizer a mesma coisa do mesmo".

Dizer "a mesma coisa do mesmo" é não acrescentar nada, é a própria inutilidade, em uma abordagem científica. Não há por que escrever um ensaio científico que fale o mesmo do mesmo, muito menos que repita o mesmo do mesmo. A ciência moderna nasce ao se dizer do outro, ao se estabelecer o sujeito como aquele "olhar de lugar nenhum", capaz de a partir deste ponto de vista - de ponto algum - discursar sobre um outro qualquer, o objeto. O sulb-jeto, o "lançado sob" o que se fala, este ponto de vista de ponto algum, exceto "sob" o que se fala, discorre a respeito de sua representação de algo, que dispõe como ob-jeto, "lançado adiante". A matriz teórica e suas hipóteses ocupam, como ponto de vista de ponto algum, a mente disposta como sujeito que de dentro do corpo "manipula" uma representação, um modelo, que se apresenta como objeto de investigação científica. Sob estas premissas "sujeito-objeto", "mente-corpo", "abordagem científica", faz todo o sentido falar de utilidade. Porém estas premissas e esta utilidade não se aplicam, de modo algum, à abordagem filosófica, à filosofia, ao apreço pela sabedoria, que assim permanecem em sua inutilidade essencial.

O entendimento vuilgar só consegue ver e apreender o que se encontra na frente de seus olhos. Assim, ele quer sempre prosseguir em linha reta, passando da coisa mais próxima a que lhe é imediatamente posterior. As pessoas chamam isto de progresso. No interior de um movimento circular, o entendimento vulgar também só vê à sua maneira: ele se movimenta em uma linha circular e toma o andar por sobre o círculo como um andar em frente, até que de repente se depara com o retomo ao ponto de partida. Neste momento, ele fica, então, parado em aporia porque não há aí nenhum progresso. Mas porque o progresso é o critério de apreensão próprio ao entendimento vulgar, todo e qualquer curso circular é desde o princípio uma objeção, um sinal de impossibilidade. O fatídico é que mesmo na filosofia se opera com este argumento do movimento circular. Este argumento é o sinal da tendência de rebaixar a filosofia ao nível do entendimento vulgar.

O movimento circular próprio à filosofia não encontra o seu elemento essencial no fato de andar ao longo de uma periferia e de retomar à posição inicial. Ao contrário, ele o encontra no olhar para o centro, que só é possível no curso circular. O meio e o fundo só se abrem como o centro no e para um círculo em torno de si. A este traço circular do pensamento íllosofante está ligada a ambiguidade, que não se pode colocar de lado e que ainda menos se deixa equilibrar através da dialética. $\mathbb{E}$ característico que sempre reencontremos na filosofia e em sua história, por fím mesmo em uma forma grandiosa e genial, a tentativa de equilibrar esta circularidade e esta ambiguidade do pensamento filosófico por sobre o caminho de uma dialética. Toda dialética na fillosofia, no entanto, é a expressão de um impasse. (HEIDEGGER, 2011, p. 241-242)

Mais cedo, nesta mesma obra, Heidegger (ibid., p.232) afirma, determinado: "nos movimentamos aqui constantemente em círculo. Este é o sinal de que nos movimentamos no âmbito da filosofia". Aristóteles na Ética a Nicômaco (VI, 3) estabeleceu cinco modos de desvelamento (aletheuein): a techne (arte ou técnica), a episteme (ciência), a phronesis (sensatez, discriminação, sabedoria prática), a sophia (sabedoria) e o noûs ${ }^{15}$ (a inteligência). Consideremos a inteligência (noûs), o quinto modo de desvelamento, como subjacente e permeando os demais modos que dela emergem em gradação de translucidez cada vez maior desta mesma inteligência, até sula total prevalência, o noûs puro. Assim temos a techne e a episteme, a técnica e a ciência, como níveis mais "baixos" de atuação da inteligência. Interessante considerar que, no decorrer dos séculos, só se fez prestigiar e enaltecer estes modos de desvelamento, onde o noûs só

${ }^{15} \mathrm{Na}$ tradução livire de Heidegger $(2012 \mathrm{~b}$, p. 21): "O notar que apreende o notado". Em seguida esclarecida: "O noein (pensar) já vem à tona imediatamente junto ao começo decisivo da filosofia grega, no qual é decidido o destino da filosofia grega e ocidental, em Parmênides: o mesmo é o notar e o notado." (ibid.) 
não é de todo ignorado porque o exercício da techne e da episteme, requerem minimamente sua atuação.

A filosofia - por sua vez -, o apreço à sabedoria, não implica no abandono desses modos de desvelamento, mas de fato colapsar o "sujeito", rendendo-se ao noûs, à plenitude de seu campo de atuação em nossa psyche. A psyche, por natureza, pertence em sua parte superior ao noûs't. Logo, é muito mais um "deixar", um "não-fazer", do que qualquer esforço, qualquer agir. A abordagem filosófica em sua inutilidade em fazer, em agir - enquanto "atuação" - é o dar-se de uma metá-noia, de uma transformação de "olhar de lugar nenhum" em visão à luz do noûs. Dar-se na e pela aquiescência do noûs, ao alcance do que for contemplado, acompanhando o movimento da contemplação, alinhlhando com a ideia e, finalmente, abordando o que for com apreço à sabedoria. Jamais segundo o pensar calculativo da utilidade.

À montante do pensar, à contramão do cálculo de utilidade, é preciso muita clareza sobre este não voluntarioso "render-se" ao noûs, à contracorrente da cotidianidade mediana, vez de regra na "impropriedade" (Uneigentlichkeit), sob a regência do "a-gente" (das $\mathrm{Man}^{17}$ ). Com efeito, render-se ao noûs, a méta-noia acima mencionada, é semelhante ao fenômeno da "pororoca" no Rio Amazonas, quando a maré do oceano avança por si mesma rio adentro. Em sua cotidianidade, que não é ninguém, uma corrente de entes vêm-de-encontro na abertura do Dasein primordialmente no modo de "utilidade" (Zuhandenheit). A esta "corrente utilitarista" cotidiana, regida pelo a-gente (das Man), contrapõe-se sempre uma "resolução" (Entschlossenheit), sendo o Dasein cada vez meul, que antecipa a possibilidade única de "pensar" e "ser" enquanto o "mesmo", como afirma Parmênides nos Fragmentos V e VIIII, geralmente traduzido por "porque pensar e ser são a mesma coisa". Porém assim interpretado a fundo por

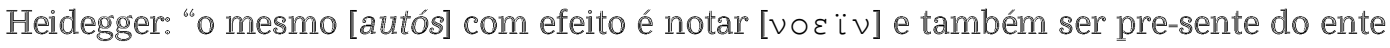
pre-sente $[\varepsilon i \vee \propto \iota]$ ".

Todos os dois se entre-pertencem, e isso de tal maneira que aquiele nomeado primeiro - vo $\tilde{\imath} \nu$ - tem seu ser nisto, que permanece ordenado ao ser pre-sente do ente pre-sente. O ćóv, o ser presente do ente pre-sente, guarda portanto o

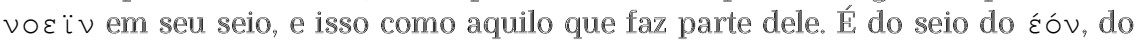
seio do ser pre-sente do ente pre-sente, que fala a duplicidade dos dois. É dela que por sua vez vem o Apelo que chama ao ser do pensar e que deixa entrar este em seu ser e o protege em seu seio.

Há uma con-cordância (de con-cordis) entre pensar e ser, ou seja, há ưm "mesmo" e único coração a "notar que apreende o notado" e a "ser pre-sente do ente presente". Na ausência de qualquer voluntarismo, de qualquer cálculo de ganho, vantagem ou utilidade, há simples aquiescência (noein) daquilo que é e como é, enfim, do ser. Eis a "inutilidade" que busca a filosofia, o apreço à sabedoria, dentre todos os demais modos de des-velamento (aletheuein) ordenados por Aristóteles, na Ética a Nicômaco Livro VI, capítulo 3.

\section{Conclusão}

No exercício de uma abordagem filosófica questionamos a utilidade de uma abordagem filosófica. A inutilidade da abordagem filosófica ficou demonstrada por não haver qualquer utilidade possível do pensar exercido neste ensaio. Entretanto, o que se chama "pensar" se deu, evidenciando a afirmação de Heidegger (1992, p. 24): "o que dá

\footnotetext{
16 “Assim como se vê no olho de outro homem o que faz a excelência de todo olho - sua pupila, aí onde se reflete a imagem daquele que olha -, assim também deve-se aperceber na alma de todo homem o que faz a excelência de sua alma, a saber o intelecto [noûs], a atividade a mais elevada da alma." (BRISSON, 2011, p. 1)

${ }^{17}$ Como afirma Heidegger (2012a, p. 331): "o 'sujeito' da cotidianidade". E adiante (ibid., p. 365): "A-gente, que não é ninguém determinado e que todos são, não como uma soma, porém, prescreve o modo-de-ser da cotidianidade."
} 
mais a pensar em nosso tempo que dá a pensar é que não pensamos ainda". Ainda não exercitamos suficientemente a "inutilidade" de um pensar, pois atendemos na cotidianidade de ser-aí os ditames do a-gente, privilegiando, no mais das vezes, os entes intramundanos que vêm-ao-encontro no modo de ser da "utilidade".

Este enveredamento perigoso que vemos absorver tudo que há ao nosso redor e nós próprios, retira o homem do "chão" ou ainda: retira do homem, o chão, solo firme que possibiliza a existência coletiva, direcionando, através de uma experiência técnica com tudo, a centralização no indivíduo. A primazia da razão instrumental, calcada na relação custo-benefício e eficiência máxima, reivindica também uma innterpretação empobrecida do que significa "ser" humano, reduzido às suas propriedades materiais e uma concepção de logos puramente instrumentalizado em função do cálculo da aplicação mais econômica dos meios para determinado fim. Gilles Gaston Granger (1969, p. 124), nas linhas finais de seu livro intitulado $\mathbb{A}$ Razão, nos oferece um relato expressivo do domínio planetário da técnica, conforme discutido neste ensaio. Conta-nos Granger que nas florestas do Equador - viviam tribos indígenas sem contato com civilização. Certo dia, chegam em seus domínios centenas de caminhões, escavadeiras e bulldozers que, à serviço de uma companhia petrolífera, abrem estradas, perfuram poços, subvertem a floresta. Eis como os índios, estupefatos, explicam entre si o fenômeno: "Animais novos surgiram. Domesticaram os homens, que lhes obedecem e os servem como escravos. E os homens brancos os alimentam e abrem-lhes caminhos através da floresta...".

De todo modo, este mal-estar generalizado, cujo vértice acompanhamos atordoados nos dias de hoje, encontra em sua própria essência a possibilidade de uma redenção. Não se trata de uma virada voluntária, desde um sujeito-agente, capaz de subverter sua condição pela força de sua racionalidade fantasiosamente inabalável, mas da possibilidade da méta-noia antes mencionada, que assim "con-verte", ou faz retornar - "ser arrastado sem escolha de ninguém pelo qual o Dasein se enreda na impropriedade" (HEIDEGGER, 2012a, p. 737), à busca de si. "Uma busca-de-si que retrocede a partir de a-gente" (ibid.), pela transformação (méta-noia), ou "modificação existencial de a-gente-ela-mesma para o ser-si-mesmo próprio" (ibid.). Uma con-versão que "deve ser levada a cabo como um ir em busca de uma escolha" (ibid.). No sentido de um "escollher essa escolha" (ibid.), enquanto resolução (Enschlossenheit), em sendo o Dasein cada vez meu, portanto, a cada vez capaz de decisão pelo "poder-ser a partir do próprio si-mesmo" (ibid.).

\section{Referências}

ABEL, Olivier. L'éthique interrogative. Paris: PUF, 2000.

ARISTÓTELES. Ética a Nicômaco. Tradução, prefácio e notas de António de Castro Caeiro. Lisboa: Quetzal Editores, 2012.

BRISSON, Luc (dir.). Platon. Oeuvres complètes. Paris: Flammarion, 2011.

CARNEIRO LEÃO, Emmanuel. Filosofia Grega: uma introdução. Teresópolis: Daimon Editora, 2010.

CARONE, Gabriela Roxana. A Cosmologia de Platão e suas Dimensões Éticas. São Paulo: Loyola, 2008.

DE CASTRO, J. C。: DE CASTRO, M. C. Episteme, scientia e cie`ncia: uma trajetória. Revista Problemata: Revista Internacional de Filosofia. João Pessoa, v. 7, n. 2, p. 99-117, 2016. DOI: http://dx.doi.org/10.7443/problemata.v7i2.30042

DE CASTRO, J. C. A humanidade esquecida: a cie`ncia na esteira da "metafísica da modernidade". Princípios: Revista de Filosofia. Natal, v. 23, n. 42, p. 125-150, set-dez. 2016. DOI: http://dx.doi.org/10.21680/1983-2109.2016v23n42ID9046 
FOUCAULT, Michel. As Palavras e as Coisas. São Paulo: Martins Fontes, 1981.

HEIDEGGER, Martin. Qu'appelle-t-on penser? Paris: PUF, 1992.

- Phenomenological Interpretation of Kant's Critique of Pure Reason.

Bloomington: Indiana University Press, 1997.

Conferências e Escritos Filosóficos. Trad. Emildo Stein. São Paulo: Nova Cultural, 1999.

- Seminários de Zollikon. Petrópolis: Vozes, 2001.

- Caminhos de Floresta. Lisboa: Fundação Calouste Gulbenkian, 2002a.

- Ensaios e Conferências. Trad. Carneiro Leão et alii. Petrópolis: Vozes, $2002 b$.

- Nietzsche I. Trad. Marco Antonio Casanova. Rio de Janeiro: forense, 2007.

- Os conceitos fundamentais da Metafísica. Trad. Marco Antonio Casanova. Rio de

Janeiro: Forense, 2011.

. Ser e Tempo. Trad. Fausto Castilho. Campinas: Editora UNICAMP, 2012a.

- Platão: o sofista. Trad. Marco Antonio Casanova. Rio de Janeiro: Forense, 2012b.

Vérita, 2014

Contribuições à Filosofia. Trad. Marco Antonio Casanova. Rio de Janeiro: Via

KANT, Emmanuel. Crítica da Razão Pura. Trad. Manuela Pinto dos Santos e Alexandre Fradique Morujão. Lisboa: Calouste, 2001.

LUIJPEN, W. Introdução à Fenomenologia Existencial. Trad. Carlos Lopes de Mattos. São Paulo: EDUSP, 1973.

SANTOS, Milton. A Natureza do Espaço. São Paulo: HUCITEC, 1996.

SORABJI, Richard. The Philosophy of the Commentators 200-600 AD. Volume 1. Ithaca: Cornell University Press, 2005.

Doutor em Bioética (UFRJ, 2018)

Docente da UNIFESO

E-mail: joaocardosodecastro@gmail.com

Doutor em Filosofia (UFRT, 2005)

E-mail: murilocdecastro@gmail.com 